\title{
Changing spatial perception: dasymetric mapping to improve analysis of health outcomes in a megacity
}

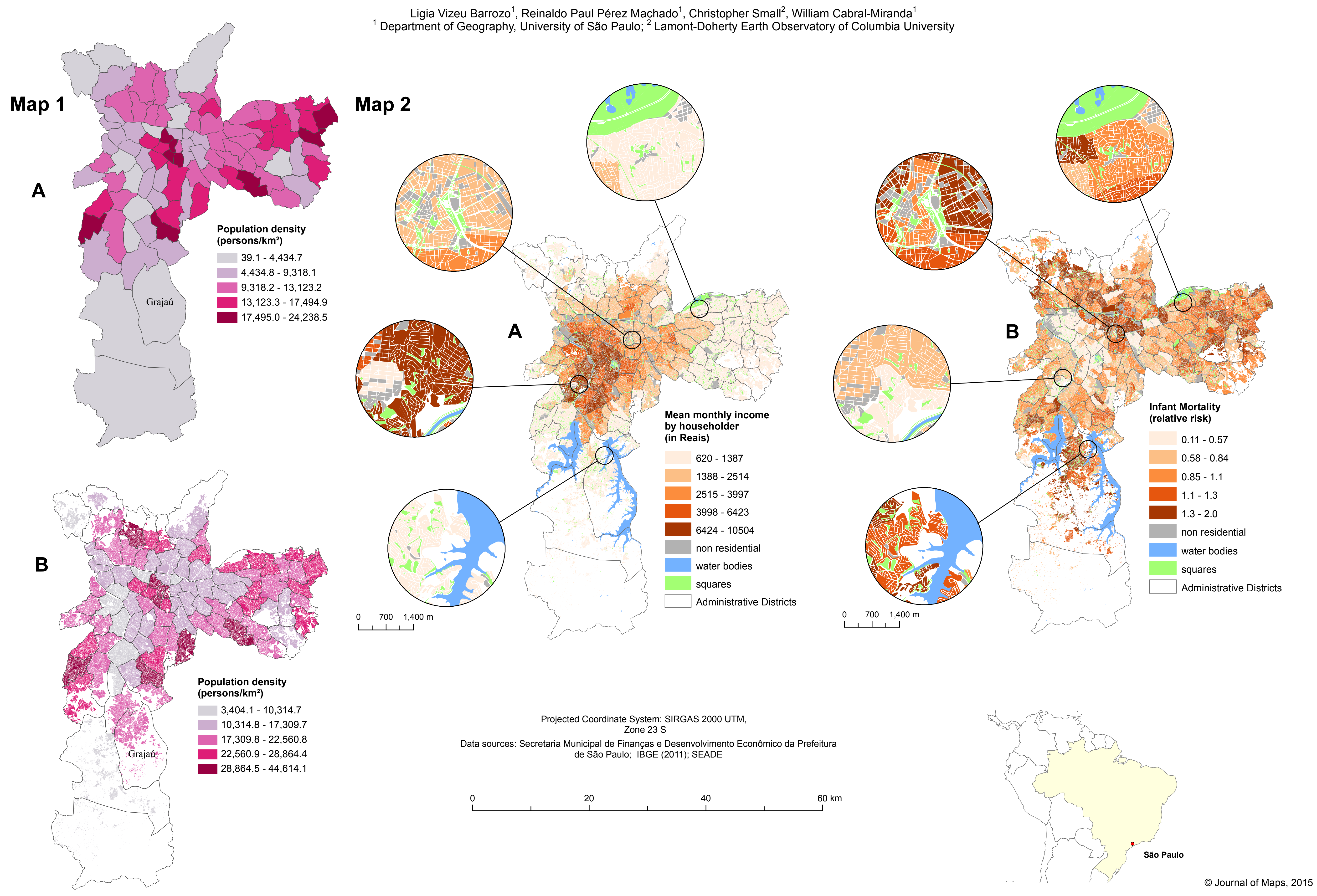

